\title{
POLÍTICA CURRICULAR NO ESTADO DE SÃO PAULO NOS ANOS 1980 E 1990
}

\author{
ROSA FÁTIMA DE SOUZA
}

rosa@fclar.unesp.br

Departamento de Ciências da Educação e Programa de Pós-Graduação em Educação Escolar da Faculdade de Ciências e Letras da Universidade Estadual Paulista - Araraquara/SP

\section{RESUMO}

Este texto apresenta um estudo sobre a política curricular implementada no Estado de São Paulo nas décadas de 1980 e 1990 para as primeiras séries do ensino fundamental. Examina o currículo prescrito cotejando-o com os contextos práticos de desenvolvimento do currícu10. A pesquisa revela que a política curricular desse período articulou-se fortemente com a produção acadêmica em educação. Ressalta ainda a continuidade na política de produção de materiais de orientação curricular nos últimos 20 anos, buscando difundir e tornar hegemônico um pensamento pedagógico inovador. Também verifica que esses materiais circularam de diferentes formas na rede de ensino e foram apropriados de maneira seletiva pelos professores que adotaram, sobretudo, as indicações práticas.

ESCOLA PÚBLICA - QUALIDADE DE ENSINO - SÃO PAULO - CURRÍCULOS

\section{ABSTRACT}

CURRICULARPOLICYIN THESTATE OFSÃO PAULO IN THEEIGHTIES AND NINETIES. Study on the curricular policy for the first grades of elementary school implemented in the State of São Paulo in the eighties and nineties. It examines the prescribed curriculum by comparing it to the practical contexts of curricular development. The research reveals that the curricular policy of that period was very much connected with academic production on education. It further emphasizes continuity in the policy of producting curricular orientation materials in the last 20 years, in order to advertise and make hegemonic an innovative pedagogical thought. It was also verified that these materials circulated in many different ways within the education system and were selectively appropriated by the teachers who particularly adopted the practical indications.

PUBLIC SCHOOLS - TEACHING QUALITY - SÃO PAULO - CURRICULUM

$\bigcirc$ artigo compreende síntese parcial de pesquisa mais ampla, intitulada "Política Curricular no Brasil: medidas de inovação e melhoria da qualidade do ensino básico nas décadas de 1980 e 1990", financiada pela Fundação de Amparo à Pesquisa do Estado de São Paulo - Fapesp. 
No início da década de 1980, embora ainda estivessem em vigor as diretrizes gerais para o currículo estabelecidas pela Lei n. 5.692/7I, começaram a surgir iniciativas governamentais de revisão e reformas curriculares em vários estados brasileiros'.

Esse movimento de reformulação curricular é representativo do jogo de determinações e iniciativas que envolvem os agentes educativos na concretização do currículo. Nesse caso, as iniciativas estaduais foram antecipatórias em relação à ação do poder público federal e reafirmaram a potencialidade criativa dos sistemas estaduais de ensino.

Não obstante, na década de 1990, observamos o movimento contrário. Nos últimos anos acentuou-se, visivelmente, a atuação do governo federal no âmbito das prescrições curriculares em todos os níveis de ensino que passou a assumir, inclusive, competências que vinham sendo historicamente exercidas no âmbito dos governos estaduais, tais como a produção de materiais de orientação curricular para o ensino fundamental e médio².

Dado que a política curricular constitui um aspecto específico da política educacional, sua investigação significa, de certa maneira, uma avaliação dos condicionantes da possibilidade que tem o Estado de provocar/influenciar mudanças na prática educativa e, como decorrência, promover a qualidade da escola pública. De fato, aquilo que se define como legítimo para ser transmitido, ensinado e aprendido nas escolas, não é questão menor, mas se coloca no centro mesmo da definição de uma política cultural de repercussões a longo prazo. Por isso, a atuação do Estado em relação ao currículo não se limita a prescrever a seleção cultural mediante dispositivos legais. A política curricular envolve também a elaboração de meios - material de orientação e controle -, que visam apresentar aos sistemas de ensino e aos professores o currículo prescrito, indicando com um pouco mais de especificações, as finalidades, os conteúdos e o modo de ensinar (metodologia e avaliação).

Esses materiais direcionam a produção de livros didáticos que servem efetivamente como orientadores do desenvolvimento do currículo; eles também exercem um papel relevante na formação inicial e continuada de profes-

I. Reformas curriculares foram realizadas nos estados de Minas Gerais, Paraná e Rio de Janeiro. Uma avaliação geral dessas reformas encontra-se em Cunha ( $99 \mid$ ).

2. Ver, por exemplo, os Parâmetros Curriculares Nacionais (Brasil, 1997). 
sores, constituem a referência para a avaliação e controle do conhecimento nos sistemas educativos e intervêm na prática educativa (Gimeno, 1998).

Este texto analisa aspectos da política curricular implementada pelos governos do Estado de São Paulo nas décadas de 1980 e 1990. Examina, especialmente, as orientações curriculares produzidas pela Secretaria de Educação do Estado de São Paulo para as quatro primeiras séries do ensino fundamental. $\bigcirc$ estudo compreende também uma análise sobre a apropriação e uso desse material pelos profissionais da rede pública de ensino.

\section{A REESTRUTURAÇÃO CURRICULAR NO ESTADO DE SÃO PAULO}

A reestruturação curricular no Estado de São Paulo iniciou-se com a implantação, em 1983, do ciclo básico (Decreto 21 .833, de 21.12.1983), concebido como o ponto de partida para a reorganização da escola pública de $1{ }^{\circ}$ grau (Pedroso, 1991; Bonel, 1993; Monteiro, 1996). Do ponto de vista político, o projeto visava diminuir a seletividade escolar, cumprindo o compromisso do governo de São Paulo com a democratização do ensino e, da perspectiva pedagógica, trazia significativas transformações para a prática da alfabetização nas séries iniciais.

Documento produzido pela equipe da Coordenadoria de Estudos e Normas Pedagógicas - Cenp (São Paulo, 1986) - historia o projeto de implantação do ciclo básico nos seguintes termos: a reorganização, mais que uma medida administrativa foi considerada uma diretriz pedagógica a ser assumida por todos os agentes da educação. A proposta do ciclo básico pressupunha uma concepção sobre a aprendizagem da língua escrita diferente da visão predominante em que a escrita era tomada como um código de transcrição do sonoro para o gráfico. A concepção inovadora adotada pela proposta entendia a língua escrita como a compreensão da representação em que a grafia das palavras e seu significado estavam associados.

Partia ainda de uma definição da prática pedagógica em que o professor deveria dominar não só o conhecimento do objeto de aprendizagem, mas também levar em conta o processo de construção do conhecimento pelo aluno. Conseqüentemente, a proposta indicava a avaliação reagindo contra a prática seletiva e reafirmando o seu caráter diagnóstico e qualitativo. 
passo seguinte da reestruturação curricular paulista $^{3}$ foi a elaboração das propostas curriculares para o ensino de $1^{\circ}$ grau que ocorreu a partir de 1985. Como demonstra Martins (1996), as versões preliminares das propostas curriculares contemplaram as sugestões de novas abordagens teóricas e metodológicas das diferentes áreas do conhecimento que eram produzidas ou divulgadas nas principais universidades paulistas.

Por algum tempo, a equipe da Cenp discutiu qual deveria ser a forma de apresentação do novo currículo aos professores, isto é, deveria ter o formato de um guia ou de uma proposta? Por fim, optou por apresentar uma proposta flexível, que concebia o professor como um intelectual e incidia sobre as matérias do núcleo comum. A maior parte das propostas curriculares foram construídas entre 1986 e 1987 e distribuídas à rede de ensino público a partir de 1988, com exceção da proposta de História que provocou grande celeuma, motivando a elaboração de várias versões preliminares até chegar à proposta definitiva em 1992.

As propostas curriculares foram apresentadas em forma de fascículos um para cada conteúdo do núcleo comum. Informadas pelo paradigma dinâmicodialógico, como atesta Palma Filho (1989), as propostas incorporaram os princípios das teorias críticas do currículo, explicitando valores políticos e sociais, declarando o compromisso com as classes populares, favorecendo a apropriação do saber sistematizado e a qualidade do ensino público.

As propostas foram construídas supondo um professor estudioso e um intelectual e estruturadas visando explicar, informar, formar e persuadir os professores. $\bigcirc$ discurso construído dirigia-se a um professor-leitor portador de vasto domínio no campo pedagógico e em sua área de conhecimento. Todas as propostas buscaram reconstituir historicamente o processo de sua construção. Além disso, elas reafirmavam sua diferença político-pedagógica em rela-

3. As indicações que serão feitas neste texto fundamentam-se na dissertação de mestrado de Palma Filho, um dos poucos estudos existentes que apresenta uma visão detalhada e ao mesmo tempo de conjunto sobre a reforma curricular do estado de São Paulo. $O$ autor foi coordenador da Cenp no período de 1983 a 1987, por isso a pesquisa apresenta a visão de um dos atores do processo de reestruturação curricular. Outros estudos incidem sobre o processo de construção das propostas curriculares de disciplinas específicas, como é o caso dos trabalhos de Martins ( 1996), sobre a proposta de História e Kawasaki ( 1991) sobre a proposta de Ciências. 
ção aos guias curriculares ${ }^{4}$ e a direção político democrática do contexto em que foram geradas.

\section{A PRODUÇÃO DA SEE/SP NAS DÉCADAS DE 1980 E 1990}

Nas décadas de 1980 e 1990, a Secretaria de Educação do Estado de São Paulo, implementou políticas de produção de materiais de orientação curricular direcionadas para os professores, visando subsidiar a prática docente na implementação do projeto de reorganização da escola de $1^{\circ}$ grau. Vários desses materiais foram utilizados pela administração em cursos de formação continuada de professores.

Qual o significado desses textos no conjunto da literatura educacional? Em primeiro lugar, esse material pode ser visto como uma modalidade de texto didático para a formação de professores em serviço. Nesse sentido, constituem objetos culturais de transmissão de saberes. Trata-se, portanto, de dispositivos pedagógicos que buscam instituir um discurso educacional e informar a prática. Podem ser vistos ainda como auxiliares do ensino, na medida em que muitas publicações trazem sugestões de atividades para os professores desenvolverem em sala de aula. No decorrer deste texto procuraremos analisar os saberes aí veiculados e sua finalidade.

Contudo, para se compreender as condições de produção, circulação e uso desses textos, é preciso ter em vista sua natureza institucional. De fato, eles são produzidos pelo Estado e funcionam como dispositivos de intervenção deste sobre a prática docente e como estratégia de formação indireta de professores. De natureza prescritiva, instituem um discurso político-pedagógico. Assim, constituem-se, a um só tempo, objetos culturais e educacionais, material de circulação de modelos pedagógicos, teorias educacionais e de práticas educativas. Dessa forma caracterizam-se também pela veiculação de valores, ideologias e conhecimentos. Entre outros textos, constituem um produto no mundo da edição, uma mercadoria singular financiada pelo Estado e distribuída gratuitamente aos seus consumidores, ou seja, as escolas e os profissionais da educação.

4. Os Guias Curriculares para o Ensino de $1{ }^{\circ}$ Grau foram elaborados na década de 1970 para orientar a implantação da reforma do ensino estabelecida pela Lei 5.692/7I. Ver Silva e Arelano (1987) e Palma Filho (1989). 
As publicações da Cenp e da Fundação para o Desenvolvimento da Educação - FDE -, ligada à Secretaria de Estado da Educação de São Paulo, têm sido divulgadas nas escolas da rede pública de ensino em tiragens em torno de 30 mil exemplares, várias delas contando com diversas edições e reimpressões. Esse material de natureza institucional foi responsável pela difusão e propaganda da política pedagógica dos governos paulistas e pela formação contínua de milhares de professores. A multiplicidade de significados políticos, instrumentais e educacionais desse material torna-o especialmente relevante para o estudo das políticas curriculares nos últimos anos.

\section{Orientações curriculares: práticas discursivas sobre políticas e inovações educacionais}

Para a investigação proposta foram selecionados 46 títulos encontrados na Oficina Pedagógica da Diretoria de Ensino de Araraquara, no interior do estado, correspondendo à maioria dos materiais produzidos pela Secretaria de Educação do Estado de São Paulo para as quatro primeiras séries do ensino de $1{ }^{\circ}$ grau, no período entre 1980 e 1997. Nesse conjunto de textos, foi possível identificar três tipos de produção: a. os subsídios para a implantação dos guias curriculares que continuaram a ser produzidos até 1984; b. textos de fundamentação mais teórica sobre o ciclo básico, destacando-se as produções do Projeto Ipê; c. textos de fundamentação teórico-prática.

Ao iniciar a década de 1980, a Cenp continuava a executar o projeto de elaboração dos Subsídios para a implementação dos guias curriculares. Os subsídios foram construídos com uma linguagem bem coloquial; apresentavam-se sob a forma de manuais para o professor, como um "receituário" indicando a distribuição do conteúdo, do tempo, a avaliação e até palavras que o professor deveria usar. Era enorme, portanto, o grau de detalhamento e especificação, buscando direcionar e controlar a prática docente.

A implantação do ciclo básico, a partir de 1984, exigiu da Secretaria de Educação de São Paulo iniciativas de capacitação de professores, uma vez que a proposta de ciclo significou não apenas uma reordenação da organização pedagógica, união da $1^{\mathrm{a}}$ e $2^{\mathrm{a}}$ séries e desseriação, mas, essencialmente, uma nova forma de trabalhar a aprendizagem da leitura e da escrita. Ainda não se tratava de uma nova concepção metodológica, mas de uma nova concepção 
teórica sobre o processo de alfabetização, concepção esta de certa forma revolucionária dentro dos padrões predominantes na época.

A necessidade de discutir com o conjunto da rede o novo referencial teórico que dava suporte à nova alternativa de alfabetização se impôs. Um primeiro conjunto de materiais impressos produzidos pela Cenp sobre o ciclo básico surgiu com a criação do Projeto Ipể. Esse material buscou apresentar, em linhas gerais, as concepções principais sobre a concepção de alfabetização, os problemas ou mitos em torno do fracasso escolar e as novas perspectivas de trabalho com a alfabetização. $\bigcirc$ projeto priorizou também a produção de textos de fundamentação voltados para a discussão de problemas gerais da educação brasileira: seletividade da escola pública, fracasso escolar, democratização e qualidade do ensino, função social da escola pública, elaboração da Constituinte e democratização da sociedade brasileira, entre outros ${ }^{6}$. Tais publicações reuniram textos de autores de renome no campo educacional, reconhecidos como "educadores progressistas", tais como: Celso Rui Beisiegel, Dermeval Saviani, Luiz Antônio Cunha, Neidson Rodrigues, Maria Helena de Souza Patto, Elba Siqueira de Sá Barretto, Luiz Carlos Cagliari, Telma Weisz, Terezinha Nunes Carraher, entre outros.

O material do Projeto Ipê revela uma forte orientação teórica mediante a difusão de textos de autoria de pesquisadores. A perspectiva adotada pela Cenp é a de ampliar a discussão sobre temas candentes no campo educacional, com base no princípio da reflexão como elemento de transformação da

5. O Projeto Ipê foi criado com a finalidade de propiciar ampla discussão sobre o ciclo básico com os professores e especialistas de educação. O projeto envolveu um sistema de multimeios: TV e material impresso. No ano de 1984, utilizou-se a Rádio Cultura como apoio. Segundo Palma Filho (1989), em 1984, foram levados ao ar vários programas dirigidos aos professores de ciclo básico, atingindo 74.679 profissionais. Em 1985, o foco do projeto foi direcionado para a atualização e aperfeiçoamento de professores especialistas em educação, envolvendo debates sobre temas educacionais em geral. Também nesse ano, foram organizados oito mil telepostos (postos de recepção organizados), atendendo 80 mil professores do ensino público. Na opinião de Palma Filho, os textos preparados para - Projeto Ipê/l 985 já traziam a discussão inicial sobre a reforma curricular, preparando o caminho para a discussão das propostas curriculares a partir de 1986.

6. Foram analisados os seguintes textos do Projeto Ipê: Ciclo básico (São Paulo, 1985); Fundamentos da educação e realidade brasileira (São Paulo, 1985a, 1985b, 1985c, 1985d, 1986b); Quem quiser que conte outra (São Paulo, 1986d); Isto se aprende com o ciclo básico (São Paulo, 1986c); A criança e o conhecimento (São Paulo, 1990a). 
prática. A Cenp valeu-se, nesse primeiro momento, do discurso e do modelo usados na formação acadêmica, reproduzindo até mesmo textos já publicados em livros e periódicos educacionais.

Os textos produzidos nesse período (meados dos anos 80) buscam também difundir o ideário de reestruturação curricular implementado pela Secretaria de Educação do Estado de São Paulo. Por exemplo, no fascículo Isto se aprende com o ciclo básico (1986d), a diretriz política é clara: a proposta curricular deve ter novos critérios de seleção de conteúdos, deve gerar efeitos na produção de livros e material didático e na orientação para a formação/atualização de professores. Parte-se da aceitação da existência de um saber sistematizado, de validade universal, como produto cultural produzido historicamente.

O processo de revisão/construção da nova proposta curricular, da mesma forma que a orientação e o apoio técnico a serem prestados, está sendo direcionado por uma vontade política que pretende buscar, na ampla escrita e na participação dos mais variados segmentos da sociedade, o critério para a escolha das medidas técnicas a serem tomadas, no sentido de promover um ensino não seletivo e de boa qualidade a toda a população. (São Paulo, 1986c, p. 19)

Outros temas bastante enfatizados foram a construção do projeto pedagógico da escola e a gestão democrática e participativa.

A repetição foi outra característica marcante da produção editorial da Cenp. Tanto os princípios teóricos e pedagógicos da proposta de alfabetização do ciclo básico quanto as diretrizes políticas da Secretaria da Educação para a reorganização da escola pública foram incansavelmente reafirmados em todas as publicações.

O saber pedagógico difundido por esse material de orientação curricular articulou-se com a difusão e propaganda das iniciativas da Secretaria da Educação e do governo do Estado de São Paulo, confundindo-se, em alguns momentos, com o proselitismo político. $O$ poder público ancorou suas proposições na produção científica, ou seja, no discurso competente valendose da legitimidade conferida pelo saber acadêmico.

Contudo, os entraves à implementação do ciclo básico nas salas de aula trouxeram para o debate educacional os desafios e limites da inovação curricular. Os educadores universitários, assessores da Cenp e a equipe técnica 
desse órgão, logo perceberam que a mudança da prática docente compreendia um processo complexo e lento. Também perceberam a insuficiência do modelo de capacitação que motivava a reflexão sobre a prática, mas não oferecia indicações para a ação. A questão já vinha sendo apontada em textos anteriores. Em um dos textos da coletânea Isto se aprende com o ciclo básico (São Paulo, 1986c), Telma Weisz assinalava a necessidade de construção de novos modelos de capacitação e, por decorrência, novos modelos de produção de material didático para a formação continuada de professores. Vários textos dessa coletânea buscaram apontar exemplos passíveis de aplicação em sala de aula, estratégia reincidentemente utilizada para demonstrar a possibilidade real de construir uma prática inovadora e, dessa forma, persuadir os professores da possibilidade da mudança.

No final da década de 1980, a Cenp passou a investir na produção de outro tipo de material, com novas características em relação à composição gráfica e configuração lingüística. $\bigcirc$ ideal da articulação teoria-prática, mencionado insistentemente nos textos do início da década de 80, era viabilizado mediante nova forma de elaboração e produção dos textos em que os conteúdos, mais simplificados, falavam ao professor de uma prática fundamentada teoricamente, cuja teoria era, porém, mostrada implicitamente. Outra mudança dizia respeito ao suporte material do texto (o livro) trazendo maior número de ilustrações, com o intuito de tornar o material mais agradável ao leitor.

Os primeiros materiais produzidos de acordo com essa nova concepção foram os dois volumes do Ciclo básico em jornada única: uma nova concepção de trabalho pedagógico. $\bigcirc$ primeiro volume (1 988) trata dos recursos didáticos e sua utilização e o segundo volume (1990) versa sobre a articulação da teoria e da prática. Especialmente o volume 2 (São Paulo, 1990), utiliza como recurso narrativo o relato de experiências e depoimentos de professores. Uma parte do material faz um balanço sobre o processo de implantação do ciclo básico no Estado de São Paulo, retratando resultados e dificuldades. A outra parte transcreve relatórios de professores, ilustrados com produções de textos, realizadas por alunos em situação de sala de aula.

Outros dois textos - Por trás das letras e Ler e escrever, um grande prazer! - compreendem o que de melhor foi produzido pela Secretaria da Educação do Estado de São Paulo sob essa nova concepção de material para formação continuada de professores. Não por acaso, é esse o material mais conhecido pelos professores e coordenadores nas escolas. 
Por trás das letras (São Paulo, 1992) foi concebido por Telma Weisz, para servir de apoio à capacitação em serviço de professores alfabetizadores $^{7}$. O fascículo foi estruturado em razão das modalidades de textos que podem ser trabalhadas nas salas de alfabetização, destacando-se a reescrita de histórias, canções, parlendas, poemas, textos de jornais, entre outros.

Ler e escrever, um grande prazer! (São Paulo, 1993) foi concebido por Beatriz Cardoso com a colaboração de Madza Julita Nogueira. Toda a produção gráfica do texto busca torná-lo agradável, bonito e divertido de forma a cativar o leitor. Para tanto, são utilizados vários recursos: o uso da linguagem de quadrinhos, fotos das autoras, inúmeras ilustrações, letras coloridas, destaques no texto e chamadas. De acordo com suas autoras, elas tomaram como eixo de construção do texto a análise de situações práticas de trabalho em sala de aula, buscando estimular uma reflexão sobre a prática. Por isso, valeram-se da colaboração de uma professora da rede estadual de ensino, a Professora Marialva, que possibilitou a coleta de dados em sua sala de aula. As experiências diárias dessa professora são trazidas para discussão, suas estratégias de trabalho, suas tentativas, seus ensaios e erros, suas concepções sobre o ensino e a aprendizagem. Tais experiências não constituem em si um relatório, mas exemplificações fragmentadas do real problematizadas como interlocução.

Ainda, entre o material que visava articular teoria-prática, encontra-se a coleção Prática pedagógica, produzida no início da década de 1990, com o intuito de oferecer sugestões de atividades para operacionalizar alguns dos conteúdos de Português, Educação Artística, Educação Física, Ciências, Geografia e História.

7. De acordo com Telma Weisz, esse texto foi fruto de um projeto mais amplo que se desenvolveu durante quatro anos ( $988 /$ /99 I), no âmbito do sistema estadual de ensino público de São Paulo. O projeto intitulado "Por uma alfabetização sem fracasso", objetivou capacitar cerca de 300 profissionais da alfabetização e, ao mesmo tempo, construir um modelo de capacitação docente que pudesse ser usado por esses 300 multiplicadores e por outros profissionais. O segundo eixo do projeto foi a produção de material didático para a capacitação docente de alfabetizadores. Com esse objetivo foram produzidos dois vídeos distribuídos pela FDE. O projeto foi financiado pela Ashoka: Innovators for the Public, pela Fundação Vitae e pela FDE. Os vídeos foram produzidos parte em estúdio (FDE) e parte em escolas, durante o segundo semestre de 1990. Participaram das gravações 75 crianças que cursavam pela primeira vez a pré-escola ou o ano inicial do ensino fundamental de quatro escolas públicas da cidade de São Paulo (três estaduais e uma municipal). Ver São Paulo, 1992. 
Destacam-se, ainda, as Atividades matemáticas (São Paulo, 1994, 1998 e 1998a), material dos mais utilizados pelos professores de $1^{a}$ a $4^{a}$ séries, considerado por coordenadores e professores como de excelente qualidade. Compreendem quatro volumes: dois para o ciclo básico, um para a $3^{a}$ e outro para a $4^{\mathrm{a}}$ série, e consistem em um conjunto de sugestões de atividades inovadoras e interessantes para o ensino da Matemática nas séries iniciais do ensino fundamental.

No final da década de 1990, diminuiu sensivelmente a produção desse material didático de orientação curricular. No governo de Mário Covas, Cenp e FDE tiveram seus quadros reduzidos e suas funções restringidas. A atenção da Secretaria da Educação voltou-se para a compra de material didático (jogos e livros) e para a formação de professores mediante a educação a distância, investindo na aquisição de antenas parabólicas e equipamentos necessários a esse tipo de formação.

O balanço da produção dos últimos 20 anos revela a continuidade nas orientações curriculares e uma perspectiva de inovação ancorada no pensamento progressista da área, pondo em destaque o papel dos intelectuais e das universidades na produção e circulação de idéias e modelos pedagógicos. Podese dizer que as orientações curriculares tiveram um papel relevante na divulgação do pensamento de alguns autores e teorias educacionais nesse período. Ressaltam-se, ainda, os esforços de produção de material mais adequado aos interesses e necessidades dos professores.

\section{INOVAÇÃO CURRICULAR E OS DESAFIOS PARA A PRÁTICA DOCENTE}

Para compreender os contextos práticos de desenvolvimento do currículo, a pesquisa buscou verificar as repercussões e influências das orientações curriculares (o currículo prescrito) na prática docente e identificar como ocorre a circulação de modelos pedagógicos e os usos que os profissionais da educação fazem das orientações curriculares emanadas dos órgãos da administração do ensino.

Para tanto, foram recolhidos depoimentos de coordenadores e professores de $I^{\mathrm{a}}$ a $4^{\mathrm{a}}$ séries da rede estadual de ensino de Araraquara, além do depoimento de um Assistente Técnico Pedagógico - ATP -, da Oficina Pedagógica, que orienta as escolas da região. Dessa forma, foi possível confrontar a visão 
de três tipos de profissionais que lidam com a inovação curricular e com a operacionalização do currículo8.

Em relação ao planejamento escolar, as Propostas curriculares para o ensino de $1{ }^{\circ}$ grau continuam sendo a referência básica para os planos de ensino, apesar da existência dos Parâmetros Curriculares Nacionais - PCNs (Brasil, 1997) -, divulgados no final dos anos 1990, uma das coordenadoras entrevistadas afirma que embora as propostas estejam em vigor há muito tempo, muitas delas não foram colocadas em prática. $\bigcirc$ planejamento segue as orientações da Secretaria da Educação que tem enviado, a cada início de ano, um encarte para orientar as discussões.

Em relação às propostas curriculares, a assistente técnica da Oficina Pedagógica afirma:

São Paulo (referindo-se à Secretaria Estadual de Educação) não força essa coisa da proposta, não se fala mais em proposta... e também os PCNs... não existe uma imposição neste sentido, não. Mas as coisas que eles vão soltando têm a ver. A capacitação do Saresp também é em cima das propostas curriculares, mas ninguém fala em propostas curriculares. Mas se percebe. A capacitação da aceleração, toda a proposta das matérias, são feitas com base nas propostas curriculares. Mas ninguém diz que retomou as propostas.

Percebe-se, portanto, existir uma orientação indireta da Secretaria de Estado da Educação para o uso das propostas curriculares mediante os indicadores utilizados pelo Sistema de Rendimento Escolar do Estado de São Paulo Saresp -, seja no material sobre a progressão continuada ou no material sobre a aceleração de alunos com defasagem idade/série. Isto torna-se claro no depoimento de uma professora de I a série da Escola A:

O material é excelente [referindo-se ao material publicado pela Cenp], mas demorou. Eu acho que os frutos estão agora sendo produzidos. Demorou um tempo, alguns anos, uma década para que essas idéias fossem adquirindo consistência

8. Para efeito dessa pesquisa, foram consideradas duas escolas públicas de $\mathrm{I}^{\mathrm{a}}$ a $4^{\mathrm{a}}$ séries do ensino fundamental da cidade de Araraquara (SP), indicadas no texto como escola A e B, tendo sido entrevistados, ao todo, oito professores. 
entre os professores. Hoje, em todas as escolas, eu acho, em todas as que eu passei e na que eu estou, não tem professor que já não tenha assimilado uma parte dessas idéias. Também houve uma coisa interessante, lógico que nesse tempo todo, aqueles que entraram assim com tudo adotando essas idéias... Eu, por exemplo, era fascinada por todas essas idéias novas que tinha, nem todas na hora de aplicar davam o resultado esperado. Então, aí, a gente foi peneirando, aquilo que era bom e aquilo que não era bem assim. De tudo isso surgiu caminhos mais seguros. Acho que hoje a professora está mais segura. Aquelas idéias da Cenp, não tem hoje quem não admitiu uma série de coisas. Então, hoje, se trabalha com aquilo tudo diferente do que era trabalhado em sala de aula. É na área de Português, aquela diversificação de uso de textos... Hoje, não tem quem não use a sua receitinha, a poesia, a música e tudo mais. Então acho que... ० AM (referindo-se às Atividades matemáticas), por exemplo, é usado, em parte, e na prática foi absorvido pelos próprios livros didáticos. (P4A)

Nesse depoimento podemos observar como a circulação de modelos corporifica-se em práticas e suportes materiais. Na verdade isto exemplifica formas de apropriação dos modelos que os professores fazem pela adoção de atividades práticas de caráter inovador. Outro aspecto da apropriação é feito mediante a produção de livros didáticos. Nesse sentido, vemos como as editoras são ágeis ao incorporarem as inovações curriculares no material de uso direto do professor e dos alunos.

$\bigcirc$ uso do material produzido pela Secretaria da Educação é seletivo. A maioria dos professores entrevistados disse ter tido poucas chances de participar de cursos oferecidos pela Diretoria de Ensino por meio da Oficina Pedagógica. Quanto ao material existente na escola, ele é utilizado por alguns professores. Este emprego, muitas vezes está condicionado à intermediação da coordenação que apresenta o material, utiliza-o nas reuniões de HTP ou sugere o seu uso. De acordo com a ATP, em muitas escolas o material enviado pela Diretoria de Ensino desaparece, em outras, fica guardado pelo(a) diretor(a) não sendo disponibilizado para consulta.

$O$ interesse dos professores sobre o material recai sobre aqueles que oferecem algum tipo de sugestão de atividades. Não por acaso os AMs (Atividades matemáticas) são o material mais citado e conhecido pelos professores. Outro material citado é a coleção Prática pedagógica. Um professor (P8B) dis- 
se utilizar o material da jornada única ("aqueles caderninhos, um de capa azul e o outro cor-de-rosa claro"). Vários professores se referiram ao material da aceleração como excelente.

Ali na Oficina Pedagógica vira e mexe eu vou lá pegar material, por exemplo, as Propostas Curriculares. Eu peguei, por exemplo, os AM de Matemática. Tive que xerocar todos. Aquele material é riquíssimo e ninguém pode ter acesso. Eu pego fita de vídeo... Eu uso o material da aceleração porque ele tem todo um contexto que explica aquele conteúdo. (P3A)

Eu conheci o AM lá em Tabatinga na escola do Planalto. Eu tinha uma colega que tinha feito o curso, acho que tinha feito um curso na Delegacia de Itápolis em anos anteriores. Então ela tinha uma pasta com todo o material. Foi um curso prolongado, eles estudavam aquele material; ela tinha tudo e me passou. Então eu comecei a fazer algumas coisas mas ainda experimentando. Depois quando eu vim para Araraquara, uma amiga me deu um exemplar. Na escola, até então, eu não tinha tido contato com esse material a não ser através da minha colega. Aí eu usava. Eu usei o ano todo. (P2B)

Esse material é muito bom [referindo-se ao material da Aceleração]. Ele tem variedade, eu não falo que sigo ele, porque não sigo nada, nem o livro que eu tenho na sala de aula. Mas eu digo, é um referencial para você trabalhar, por exemplo, você quer trabalhar com poesia, então tem várias poesias lá que você fala assim: olha que poesia interessante eu não tinha pensado nisso para trabalhar. Aí você quer trabalhar um texto sobre água. Ele já trabalha o texto sobre água e já fala sobre poluição, poluição do ar e envolve muitas coisas. Então você fala: olha que interessante procurar um texto que já fala sobre tudo isso. Trabalha com jornal, trabalha com receitas, acho que ele dá caminhos para você fazer diferente. (P6B)

Para o professor conta efetivamente o material que ele possa utilizar na orientação do seu trabalho. Na maioria dos depoimentos, os professores dizem ter construído sua prática mediante o exemplo, a orientação de professores mais velhos. Um professor relata como se tornou alfabetizador durante quatro anos no início da década de 1990.

Eu procurei a ajuda de professoras mais antigas, de uma ex-professora minha do primário, que deu aula para mim na I a série. Então imagina como eu comecei! 
Comecei procurando a ajuda da minha professora do primário, uma professora assim, respeitada, que tinha todo um comprometimento profissional, séria, considerada uma ótima professora, mas tinha uma postura mais tradicional e eu fui seguindo as orientações dela. (PIA)

Pergunto a ele se não teve contato com o material do ciclo básico quando atuou como professor de $1^{\mathrm{a}}$ série.

Este tipo de material não era encarado com seriedade pela equipe dos professores e pela direção. Acho que principalmente pela direção porque a gente fazia reunião e era aquela coisa, lia uns trechos, pulava outros e o diretor tinha que se ausentar; então os professores se comprometiam a terminar de estudar, mas sem ter tarefas posteriores, uma discussão alguma coisa assim para a gente estar consolidando o que tinha lido... aí eu não sei. $O$ diretor saia para fazer alguma coisa, aí ninguém lia e mentia que tinha lido na hora que ele chegava, eu vi muito disso. (PIA)

A construção da prática é tecida em múltiplos espaços e contextos: o exemplo e o aprendizado com as colegas, o uso de material didático, em processos de formação continuada, na leitura das orientações curriculares, no Horário de Trabalho Pedagógico - HTP -, nos cursos de formação inicial para professores. Como se observa no relato anterior, o professor iniciou sua carreira no magistério como professor alfabetizador oito anos após a implantação do ciclo básico na rede pública de ensino paulista. No entanto, sua atuação inicial foi pouco influenciada pelas idéias em circulação naquela época, o que revela as dificuldades de efetivação das inovações e os seus processos heterogêneos de apropriação. Ainda de acordo com o relato desse professor:

Eu parti de diário velho de professor, de cartilha, isto que me foi oferecido no início, mas fazia aquilo porque estava aprendendo a fazer. Mas eu não ficava muito satisfeito, não gostava; então eu fui começando a modificar algumas coisas por conta própria e... também por conta dessas orientações que participava (referindo-se aos cursos oferecidos na Oficina Pedagógica), ouvia uma coisa aqui, outra coisa ali, sempre havia algum texto lá pra estar lendo, fazendo reflexão, então eu ia procurando introduzir algumas mudanças na minha prática pedagógica. (PIA) 
Vemos assim, como os professores utilizam-se de vários recursos no seu processo de profissionalização. A experiência relatada nos dá idéia da forma multifacetada pela qual ocorre a apropriação dos textos e dos modelos pedagógicos.

Na verdade, os professores têm um preconceito contra a teoria, que me dói... Então precisa da teoria e os professores acham que não necessitam. Ainda a gente tem muito disso, eu fico assustada principalmente com o PEB II... gente, eles não gostam de ler, não gostam de escrever... A maioria dos professores gosta da prática, de como eu faço! Como eu faço?... Quais foram as mentiras que contaram pra gente... Eles não querem discutir, eles perguntam como é que eu faço. Eles não são capazes de perceber que é a teoria que vai me dar as chaves do como fazer. (ATP)

A ATP enfatiza os textos novos produzidos pela Cenp dentro daquela concepção de articulação teoria-prática. Nesse depoimento sobressai um dado interessante: a relação que os profissionais da educação mantêm com a questão da inovação educacional. De acordo com a assistente, embora os professores sejam resistentes à teoria e às mudanças, eles preferem sempre o que há de mais novo, a última novidade. Talvez seja esse o motivo pelo qual o pensamento pedagógico dos últimos 20 anos venha se reatualizando constantemente nos textos e nos suportes materiais de divulgação. Em sua opinião, a inovação dá uma idéia de que se está fazendo o novo e também a aparência de busca de mudança.

De fato, esse tipo de atitude é um efeito do discurso educacional veiculado a partir da década de 80, o qual, construído sobre a insígnia do novo e da mudança, instituiu a visão negativa de qualquer sentido vinculado ao "tradicional" em educação.

Os depoimentos dos educadores revelam que a apropriação dos textos ocorre em muitos níveis. No âmbito da escola, as idéias são incorporadas primeiro no planejamento e, de forma mais lenta, na prática educativa. Os usos e apropriações das políticas de inovação curricular dependem de vários fatores vinculados ao exercício da prática educativa. A organização do trabalho no interior da escola é fator importante na medida em que a direção e coordenação podem facultar ou não o acesso aos materiais existentes. A formação inicial, aliada aos interesses e motivações pessoais dos professo- 
res, exerce um papel fundamental. De tudo isso, o vínculo com a prática é o fator mais determinante.

Portanto, as orientações curriculares, para serem eficientes, devem se constituir em textos que falam diretamente ao professor, na linguagem que ele entenda, e que contenha articulações com a sua prática. Os desafios da inovação curricular encontram-se justamente nesse ponto, pois, se a compreensão dos fundamentos de um ideário pedagógico inovador é fundamental para a mudança da prática, não podemos desconsiderar a força da razão prática implícita na ação docente. Conforme afirma Perrenoud (1993), a prática nunca é mera concretização de receitas, de modelos didáticos ou de esquemas de ação. Ela é dirigida pelo habitus do professor, pelos sistemas de pensamento e de ação que alicerçam as inúmeras dimensões da sala de aula. Por isso, a mudança da prática passa tanto pela transformação do habitus como pela disponibilização de modelos de ação. Essas mudanças resultarão, segundo o autor, mais da modificação de constrangimentos e de possibilidades objetivas do que da difusão de idéias e métodos.

As políticas de formação e inovação curricular devem estar atentas aos processos de concretização do currículo, especialmente à passagem do currículo prescrito ao currículo em ação, sem o que as orientações curriculares podem tornar-se meros discursos configurados em textos, e a inovação e a mudança podem se tornar, tão-somente, palavras de efeito, exercícios de retórica ecoando no imaginário pedagógico.

\section{REFERÊNCIAS BIBLIOGRÁFICAS}

BONEL, M. M. O Ciclo básico: estudo de caso de uma política no Estado de São Paulo. Campinas, 1993. Dissert. (mestr.) Faculdade de Educação da Unicamp.

BRASIL. Ministério de Educação e Cultura. Parâmetros curriculares nacionais. Brasília: SEF, 1997. v. I- I0.

CUNHA, L. A. Educação, estado e democracia no Brasil. São Paulo: Cortez; Niterói: Editora da UFF, 1991.

GIMENO, J. Currículo: uma reflexão sobre a prática. Porto Alegre: Artes Médicas, 1998.

KAWASAKI, C. S. O Professor e o currículo de ciências - 10 grau. concepções de ensino em debate. Campinas, 1991. Dissert. (mestr.) Faculdade de Educação da Unicamp. 
MARTINS, M. C. A Construção da proposta curricular da Cenp no período de 1986 a 1992. Campinas, 1996. Dissert. (mestr.) Faculdade de Educação da Unicamp.

MONTEIRO, R. B. Resgatando o passado: o ciclo básico e a reprodução da reforma do ensino primário de 1967. Campinas, 1996. Dissert. (mestr.) Faculdade de Educação da Unicamp.

PALMA FILHO, J. C. A Reforma curricular da SEE/SP para o ensino de l o grau ( 1983- 1987): uma avaliação crítica. São Paulo, 1989. Dissert. (mestr.) Pontifícia Universidade Católica de São Paulo.

PEDROSO, L. A. Democracia, política e administração educacional: a proposta Montoro (1978-1984). Campinas, 1991. Dissert. (mestr.) Faculdade de Educação da Unicamp.

PERRENOUD, P. Práticas pedagógicas, profissão docente e formação: perspectivas sociológicas. Lisboa: Dom Quixote, 1993.

SÃO PAULO (Estado). Secretaria da Educação. Atividades matemáticas: ciclo básico, I . 3.ed. São Paulo, 1994.

Atividades matemáticas: ciclo básico, 2. 3.ed. São Paulo, 1998.

Atividades matemáticas: $4^{\mathrm{a}}$ série do ensino fundamental. 2.ed. São Paulo,

1998a .

Ciclo básico e a reorganização do ensino de 1 grau: sistema de avaliação.

São Paulo, 1986.

- Ciclo básico e a reorganização do ensino de 1 o grau. sistemática de avaliação. São Paulo, $1986 a$.

Ciclo básico em jornada única: uma nova concepção de trabalho pedagógico. São Paulo, 1990. (O encontro da teoria e da prática, 2)

- Ciclo básico em jornada única: uma nova concepção de trabalho pedagógico. São Paulo, 1988. (Recursos didáticos: sua utilização, I)

Ciclo básico: atualização e aperfeiçoamento de professores e especialistas em educação por multimeios. São Paulo, 1985. (Projeto Ipê)

A Criança e o conhecimento: retomando a proposta pedagógica do ciclo básico. São Paulo, 1990a. (Projeto Ipê)

- Fundamentos da educação e realidade brasileira: a difícil tarefa de repensar e construir a escola pública. São Paulo, 1985a. (Fundamentos 4, Projeto Ipê) 
SÃO PAULO (Estado). Secretaria da Educação. Fundamentos da educação e realidade brasileira: a educação, a constituinte e o projeto da escola democrática. São Paulo, 1985b. (Fundamentos 3, Projeto Ipê)

Fundamentos da educação e realidade brasileira: contatos imediatos do primeiro grau. São Paulo, 1985c. (Fundamentos 2, Projeto Ipê)

Fundamentos da educação e realidade brasileira: ...e a nossa escola é assim? São Paulo, 1985d. (Fundamentos 5, Projeto Ipê).

. Fundamentos da educação e realidade brasileira: refletindo sobre questões fundamentais para o planejamento escolar. São Paulo, 1986b. (Fundamentos 6, v.2, Projeto Ipê)

Isto se aprende com o ciclo básico. São Paulo, 1986c. (Projeto Ipê) Ler e escrever, um grande prazer! São Paulo, 1993.

Por trás das letras: intertexto. São Paulo: FDE, 1992.

Proposta educacional: currículo e avaliação. 1992a. (Série Argumento)

Quem quiser que conte outra... São Paulo, 1986d. (Projeto Ipê)

SILVA, T. R. N.; ARELANO, L. R. G. Orientações legais na área de currículo, nas esferas federal e estadual a partir da lei 5.692/7I. Cadernos Cedes, n. I3, p.26-44, 1987.

Recebido em: julho 2004

Aprovado para publicação em: outubro 2004 